\title{
ANALISIS TRANSPORTASI YANG OPTIMAL GUNA MEMINIMISASI PRAKTEK IHTIKAR PADA DISTRIBUSI PUPUK BERSUBSIDI
}

\author{
Misbahul Munir \\ Irmayanti Hasan \\ Fakultas Ekonomi UIN Maliki Malang \\ Jln. Gajayana 50 Malang Telp. 0341551354
}

\begin{abstract}
PT. Gresik as Petro Chemical fertilizer producer, has sought to meet the needs (needs), but the reality of peasant producers demand fertilizer Exes field remains a regional issue (especially in East Java), which is quite interesting to study. To illustrate the phenomenon that occurs in the process and pattern of distribution of subsidized fertilizer in certain regions (East Java) with descriptive approach and / or approach the minimum transportation cost (minimization of transportation). To analyze the economic aspects of Islam to attempt to detect ikhtikar minimization practices (hoarding of fertilizer). Islam is very concern about the issue of availability of goods and their distribution among the people, so many religious texts (both from al-Quran and the Sunnah) which expressly condemn and prohibit all forms of ihtikar (hoarding), and all forms of practice that leads to ihtikar, such as monopoly and unfair competition in the market mechanism. In fact, if there has been hoarding goods, the government has the right to force the merchants to sell goods to the prevailing standard price in the market. In fact, according to the scholars, goods stockpiled by the merchants sold their capital and merchants are not allowed to take advantage as a penalty against them. Had the traders were reluctant to sell their goods at market prices, then the law enforcement authorities (judges) may seize the goods and then distribute them to people who need them.
\end{abstract}

Keywords: Ihtikar, pendekatan biaya tranportasi minimum

Kasus riil yang ada di masyarakat, yaitu terdapatnya permintaan (demand) dengan penawaran (supply) kurang berimbang (unbalance) dan terjadi kelebihan permintaan (exes demand) yang cukup signifikan menjadikan pertanyaan besar bagi pemerhati ekonomi regional. PT. Petro Kimia Gresik sebagai produsen pupuk, telah berupaya memenuhi kebutuhan (needs) petani produsen tetapi realita lapang exes demand pupuk masih menjadi isu regional (utamanya Jawa Timur) yang cukup menarik untuk dikaji. 
Seiiring dengan perkembangan sektor industri perumahan yang membutuhkan tanah-satu sisi, dan di sisi lain petani produsen mengalami 'kesulitan' untuk memperoleh pupuk-nampaknya petani produsen tergiur tawaran industriawan untuk menjual tanah pertaniannya yang akan dijadikan kawasan industri perumahan. Hal ini mendorong eksistensi sektor pertanian khususnya ketahanan pangan akan terancam sehingga jangka panjangnya Indonesia bukan lagi bisa memperhatikan prestasi swasembada pangan tetapi justru akan menjadi negara peng-import pangan.

Agar kasus di atas dapat diatasi atau diminimisasi, maka upaya semangat PT.Kimia Gresik perlu didukung yaitu selalui ingin memenuhi kebutuhan pupuk utamanya pupuk bersubsidi. Manisfestasi dukungan ini dilakukan dengan jalan meneliti pada aspek distribusinya dengan analisis optimalisasi melalui pendekatan teori transportasi; sebagai penganalisis/pemerhati/pelaku ekonomi Islam, melalui penelitian ini atas dasar hasil analisis optimalisasi dan/atau deskripsi distribusi akan dianalisis pada sisi praktek monopoli menurut pandangan Islam atau yang disebut dengan ihtikar.

Praktek ikhtikar dapat muncul karena adanya perencanaan dan pelaksanaan tidak sinkron atau perencanaan dan pelaksanaannya sama tidak cocok sehingga ada peluang dalam melaksanakan praktek iktikar ini. Untuk itulah perlulah dianalisis secara mendalam aspek distribusi ini. Atas dasar ketidakseimbangan (unbalance) antara supply dan demand dan terjadi exes demand di muka, maka penelitian bertujuan untuk menggambarkan fenomena yang terjadi pada proses dan pola distribusi pupuk bersubsidi pada daerah tertentu (Jawa Timur) dengan pendekatan deskriptif dan/atau pendekatan biaya tranportasi minimum (minimization of transportation) dan untuk menganalisis pada aspek ekonomi Islam dengan mendeteksi usaha minimisasi praktek ikhtikar (penimbunan pupuk).

\section{Optimalisasi Melalui Pendekatan Teori Transportasi}

Ada tujuh alternatif pendekatan dalam menjawab tujuan pertama, yaitu: Metode Pojok Barat Laut (North West Corner Methode), Batu Loncatan (Stepping Stone Methode), Metode Kemerosotan (Degeracy Methode), Metode Ongkos 
Terkecil (Minimization Cost Methode), Metode Pendekatan Vogel (Vogel's Approximation Methode, VAM), Metode MODI (Modified Distribution Methode), Metode Transipment (Transshipment Methode). (P. Siagian, 1987:159186). Namun dalam penelitian ini hanya akan digunakan pilih model yang terbaik (optimal) karena asumsi kuat optimal terjadi dengan indikator pokoknya adalah model biaya minimum (Minimization Cost Methode)

Simulasi distribusi pupuk bersubsidi yang optimal dapat dilakukan dengan menggunakan teori transportasi. Teori transportasi tersebut pendekatannya melalui model-model yang mutahir, di antaranya adalah:

1. Metode Pojok Barat Laut (North West Corner Methode); NWCM adalah alat analisis transportasi khusus (the special transportation) untuk menyusun tabel awal dengan cara mengalokasikan distribusi barang mulai dari sel yang terletak pada sudut paling kiri atas.

2. Batu Loncatan (Stepping Stone Methode), tujuan dari penilaian ini adalah untuk menentukan apakah dapat dikembangkan suatu cara pengiriman dari pabrik-pabrik ke proyek-proyek secara lebih baik.

3. Metode Kemerosotan (degeracy methode); Metode degeneracy ini untuk menjawab analisis optimalisasi distribusi yang diperoleh yang tidak seharusnya dituju untuk distribusi pupuk. Secara teknis persoalan angkutan kemerosotan mendapat perhatian penting karena jawab merosot (degenerate solution) mengakibatkan ketidakmampuan untuk mengatur pengembangan semua sel (gudang penyangga) yang bukan basis menjadi basis.

4. Metode Ongkos Terkecil (Minimization Cost Methode); Metode ongkos terkecil sebuah metode untuk menyusun tabel awal dengan cara pengalokasian distribusi barang dari sumber ke tujuan mulai dari sel yang memiliki biaya distribusi terkecil.

5. Metode Pendekatan Vogel (Vogel's Approximation Methode, VAM); VAM juga sama seperti analisis NWCM adalah alat analisis transportasi khusus (the special transportation). VAM bertujuan untuk mendeskripsikan optimalisasi dengan jalan 'mencegah' ('to prevent') timbulnya kemungkinan terlewatinya wilayah yang seharusnya sebagai daerah tujuan distribusi. 
6. Metode MODI (Modified Distribution Methode); Metode MODI merupakan variasi dari metode stepping stone yang didasarkan pada rumusan dual. Perbedaannya dengan metode stepping stone dalah pada metode ini tidak harus menentukan semua jalur tertutup variabel nonbasis, kecuali pada saat akan melakukan perpindahan pengisian tabel. Dengan demikian MODI merupakan cara yang efisien untuk menghitung variabel nonbasis.

7. Metode Transipment (Transshipment Methode); Metode TM ini merupakan model umum (general model) dari transportasi, dan di break down menjadi 3 model khusus, yaitu NWCM, MC dan Vogel. Di samping itu TM merupakan alat analisis untuk menjawab persoalan optimalisasi keseimbangan (the balance of optimalization). (Siagian, 1987).

\section{Optimalisasi Distribusi dengan Pendekatan Teori Lokasi}

Masuknya "teori lokasi" ke dalam domain pembahasan ilmu ekonomi, ternyata harus melalui suatu perjalanan sejarah yang cukup panjang, yaitu dimulai sejak Von Thunen mengembangkan “teori daerah lokasi” sekitar tahun 1830, sama dengan saat Walter Isard berhasil memantapkannya dengan memperkenalkan teori lokasi secara utuh pada tahun 1952. sejak saat itu terbukalah peluang untuk memyempurnakan ilmu ekonomi dengan memperhitungkan dimensi ruang (space dimension) di dalamnya.

Tidaklah berlebihan kalau dalam konteks produksi dikatakan bahwa ilmu ekonomi telah berhasil menjelaskan pertanyaan "apa”, "berapa", "bagaimana", "siapa", dan "bilamana". Namun sayang sekali, tidak dipersoalkan "di mana" aktivitas produksi tersebut diselenggarakan. Dengan perkataan lain, berbagai analisis dalam ilmu ekonomi berada dalam kerangka alam tanpa ruang (spaceless world). Padahal, sangat jelas bahwa analisis ekonomi apapun, yang diletakkan dalam situasi wonderland of no dimensions, amatlah jauh dari kenyataan hidup. Pernyataan di atas dimaksudkan sebagai suatu catatan untuk menunjukkan arah penelitian teoritis dalma rangka penyempurnaan ilmu ekonomi, khususnya yang memperhitungkan dimensi ruang (spasial), dan sekaligus untuk mengawali pembahasan tentang teori lokasi atau "ruang”. (Azis dalam Djojodipuro, 1994).

Pada mulanya, teori-teori lokasi ini dikembangkan dalam tiga bentuk yang tampaknya masing-masing berdiri sendiri-sendiri, dengan orientasi yang berbeda- 
beda pula. Ketiga teori lokasi tersebut dapat dijelaskan secara ringkas sebagai berikut: (i) teori lokasi Von Thunen, yang berorientasi pada daerah lokasi sehingga disebut "teori daerah lokasi". Dalam teorinya ini Von Thunen mengembangkan lingkaran-lingkaran yang disusunnya berupa daerah-daerah yang efisien sebagai lokasi perusahaan tertentu yang masih harus ditentukan tempat lokasinya didalam daerah tersebut. Teori daerah lokasi yang dirintis oleh Von Thunen ini akhirnya mencari jalan sendiri, sehingga landasan bagi teori penggunaan tanah modern (modern land use theory). Tokoh-tokoh teori ini adalah : Von Thunen, Melvin Greenhut, tord Palander, dan Walter Isard; (ii) teori lokasi Launhardt, yang kemudian dikembangkan oleh Weber dalam membahas masalah penentuan tempat lokasi yang belum sempat terbahas dalam teori daerah lokasi. Karena orientasinya itu maka teori ini disebut "teori tempat lokasi”. Dalam perjalanannya, teori tempat lokasi ini kemudian ternyata berkembang dengan pesat. Tokoh-tokoh teori ini adalah : Wilkelm Laundhardt, Alfred Weber, W. Alonso, Tord Palander, Edgar Hoover, dan Walter Isard.; (iii) teori lokasi Hotelling: ketergantungan lokasi dan keseimbangan spsial. Perkembangan teori ini, sejalan dengan orientasinya, telah memberikan sumbangan penting dalam memantapkan teori ketergantungan dan keseimbangan spasial. Tokoh-tokoh teori ini adalah : Hotelling-Fetter, Fisher, Walter Isard, Christaller, dan August Losch.

Perkembangan selanjutnya teori tempat lokasi (Launhardt-Weber) bersama-sama dengan teori ketergantungan lokasi dan keseimbangan spasial (Hotelling); keduanya menyatu dalam bentuk yang disebut mikro ekonomi spasial, dan akhirnya bermuara pada Ilmu Regional (regional science) yang dimotori oleh Walter Isard, yang dalam rangka penyempurnaan ilmu ekonomi, mengusulkan penggunaan nama "ilmu ekonomi spasial" sebagai nama alternatif dari ilmu regional tersebut.

Dari tinjauan di atas dapat disimpulkan bahwa Walter Isard, yang kemudian lebih dikenal sebagai pendiri (founding father) dari Ilmu Regional, adalah tokoh yang sangat berjasa karena keberhasilannya membuat para ahli ekonomi dapat menerima "teori lokasi" sebagai bagian dari teori-teori ekonomi. Kecuali itu, keberhasilan Isard adalah menemukan mata-rantai yang selama ini 
seolah-olah "memisahkan" teori tempat lokasi dan teori daerah lokasi. (Djojodipuro, 1992).

\section{Masalah Distribusi dalam Islam}

Dalam hal-hal yang berkaitan dengan persoalan ekonomi, pada dasarnya Al Qur'an maupun sunnah hanya menetapkan prinsip prinsip pokoknya saja agar tidak bertentangan dengan nilai ajaran agama, dan selebihnya untuk pengembangan lebih jauh diserahkan kepada orang-orang yang berkompeten di bidangnya. Islam tidak hanya memberikan ruang kebebasan ekonomi (sebagaimana dalam pengertian di atas) kepada manusia untuk melakukan kreatifitas dalam melakukan kegiatan ekonominya termasuk dalam hal distribusi. (Munir, 2007).

Penetapan saluran distribusi pada perusahaan akan menyebabkan kemajuan dan kemunduran bagi perusahaannya itu sendiri. Apabila saluran distribusinya baik maka perusahaan akan tetap bertahan dan sebaliknya. Sehingga pada akhirnya, kondisi pasang surut itu merupakan sunnah kehidupan, sebagaimana firman Allah pada surat Al- Mulk ayat 2 yang artinya:

"Yang menjadikan mati dan hidup, supaya Dia menguji kamu, siapa di antara kamu yang lebih baik amalnya. dan Dia Maha Perkasa lagi Maha Pengampun.”

Pemilihan menurut bahasa adalah sebuah proses memilih hal yang lebih bagus. Sedangkan memilih saluran distribusi berarti tempat untuk memasarkan, dari pengertian tersebut, pemilihan saluran distribusi secara terminologi adalah memilih untuk menghindari sebanyak mungkin seluruh segi-segi negatif dan mendapatkan saluran distribusi (tempat memasarkan) dengan paling banyak faktor-faktor positif. Penentuan saluran distribusi yang tepat akan meminimumkan "beban" biaya (investasi dan operasional) jangka pendek maupun jangka panjang. Pemilihan dalam Islam dikenal dengan bahasa ikhtiyar yang berarti proses merencanakan dan memilih hal yang baik dan lokasi dalam Islam dikenal dengan bahasa "al makanu” yang berarti tempat. Dari uraian tersebut dapat disimpulkan bahwa pemilihan saluran distribusi dalam sebenarnya tidak jauh beda dengan pengertian pada umumnya, namun yang membedakan, ikhtiyar mengandung unsur direncanakan dan memilih. 
Distribusi merupakan komponen penting dalam pelaksanaan suatu bisnis. Diakui bahwa distribusi adalah merupakan bagian terpenting dalam ekonomi. Distribusi dalam ekonomi kapitalis terfokus pada pacsa produksi yaitu sebagai konsekuensi dari pada proses produksi bagi setiap proyek, baik dalam bentuk uang maupun nilai, lalu hasil tersebut didistribusikan pada komponen-komponen produksi yang terlibat didalamnya. Komponen-komponen tersebut meliputi upah, bunga, ongkos, dan keuntungan (Qardhawi, 2001).

Sedangkan distribusi dalam ekonomi Islam didasarkan pada 2 nilai manusiawi yang mendasar dan penting yaitu kebebasan dan keadilan. Al-Qur'an sangat banyak mendorong manusia untuk melakukan bisnis. Firman Allah dalam surat Al-Jumu' ah ayat 10:. "Apabila telah ditunaikan shalat, Maka bertebaranlah kamu di muka bumi; dan carilah karunia Allah dan ingatlah Allah banyak-banyak supaya kamu beruntung”. Al-Qur'an juga memberi pentunjuk agar dalam bisnis tercipta hubungan yang harmonis, saling ridha, tidak ada unsur eksploitasi, firman Allah dalam surat Annisa' ayat 29: "Hai orang-orang yang beriman, janganlah kamu saling memakan harta sesamamu dengan jalan yang batil, kecuali dengan jalan perniagaan yang Berlaku dengan suka sama-suka di antara kamu".

Pada umumnya, kemacetan dalam mendistribusikan barang-barang dan jasa-jasa akan banyak menimbulkan kesulitaan baik dipihak konsumen maupun produsen. Kesulitan yang akan terjadi di pihak produsen meliputi terganggunya penerimaan penjualan sehingga target penjualan yang telah di tentukan tidak dapat terpenuhi. Hal ini akan menyebabkan arus pendapatan yang dibutuhkan oleh perusahaan untuk melangsungkan kontinuitasnya tidak dapat diharapkan. Sedangkan kesulitan yang akan timbul di pihak konsumen akan menyebabkan tendensi harga yang meningkat. Tendensi harga yang meningkat terjadi akibat berkurangnya barang yang ditawarkan di pasar. Sehingga dalam pendistribusian harus mencipatan unsur-unsur yang telah diterangkan pada surat diatas tersebut.

Islam juga melarang hal-hal yang dapat menghambat proses pendistribusian yaitu: (i) Penimbunan, Islam melarang penimbunan yang dapat menghambat pendistribusian barang sampai ke konsumen. Menimbun adalah membeli barang dalam jumlah banyak yang kemudian menyimpannya dengan maksud untuk menjualnya dengan harga tinggi. Penimbunan dilarang agar barang 
tidak hanya beredar hanya dikalangan orang-orang tertentu. Sebagaimana misi Islam: "Siapa saja yang melakukan penimbunan untuk mendapatkan harga yang paling tinggi, dengan tujuan mengecoh orang Islam maka termasuk perbuatan yang salah".

Hadist tersebut mengisyaratkan bahwa perbutan yang salah, yaitu menyimpang dari peraturan jual beli atau perdagangan dalam sistem ekonomi Islam yang berdasar al-Quran dan hadist. Adapun ancaman bagi pelaku penimbunan tercantum dalam hadist di bawah ini:

Nabi Muhammad saw. bersabda "orang-orang yang menawarkan dengan harga murah akan diberi rizqi, sedangkan yang melakukan penimbunan kan dilaknat".

Kemudian Monopoli, sebagaimana sabda Rasulullah SAW:Artinya:

Rasulullah SAW bersabda :"Janganlah kamu mencegat para khalifah dan janganlah orang kota menjualkan untuk orang desa."saya bertanya kepada Ibnu Abbas, "Apa arti sabdanya?" ia menjawab, "janganlah ia menjadi perantara baginya."

Ibnu Abbas mengartikan Hadliru Libadi dengan broker ataupun perantara yang mengambil keuntungan sebanyak-banyaknya. Adapun tempat yang dilarang mencegat khalifah adalah diluar pasar atau tempat menjual barang, karena akan merugikan pedagang dipasar dan juga konsumen (Diana, 2008)

\section{Ihtikar: Sebagai Salah Satu Bentuk Rekayasa Pasar}

Rekayasa pasar dalam supply terjadi bila seorang produsen/penjual mengambil keuntungan di atas keuntungan normal dengan cara mengurangi supply agar harga produk yang dijualnya naik. Ihtikar biasanya dilakukan dengan membuat entry barrier, yakni menghambat produsen/penjual lain masuk ke pasar, agar ia menjadi pemain tunggal di pasar (monopoli). Karena itu, biasanya orang menyamakan ihtikar dengan monopoli dan penimbunan, padahal tidak selalu seorang monopolis melakukan ihtikar.

Demikian pula tidak setiap penimbunan adalah ihtikar. Bulog juga melakukan penimbunan, tetapi justru untuk menjaga stabilitas harga dan pasokan. Demikian pula dengan negara apabila memonopoli sektor industri yang penting 
dan menguasai hajat hidup orang banyak, bukan dikategorikan sebagai ihtikar. Ihtikar terjadi bila syarat-syarat di bawah ini terpenuhi: (a) Mengupayakan adanya kelangkaan barang baik dengan cara menimbun stock atau mengenakan entrybarriers; (b) Menjual dengan harga yang lebih tinggi dibandingkan harga sebelum munculnya kelangkaan; (c) Mengambil keuntungan yang lebih tinggi dibandingkan keuntungan sebelum komponen 1 dan 2 dilakukan.

Dalam ilmu fikih rekayasa pasar dalam supply disebut ihtikar, yaitu bila seorang penjual mengambil keuntungan di atas keuntungan normal dengan cara mengurangi supply agar harga produk yang dijualnya naik. Ihtikar biasanya dilakukan dengan membuat entry barrier, yaitu menghambat penjual lain masuk ke pasar agar ia menjadi pemain tunggal di pasar (monopoli). Adakalanya orang menyamakan ihtikar dengan monopoli dan penimbunan, padahal tidak selalu seorang monopolis melakukan ihtikar. Misalnya, Bulog melakukan penimbunan tapi justru untuk menjaga kestabilan harga dan pasokan. Begitu juga pemerintah yang memonopli sektor industri tertentu dan mengurangi hajat hidup orang banyak bukan dikategorikan sebagai ihtikar. Ihtikar terjadi bila syaratnya terpenuhi. Adapun persyaratannya yaitu, mengupayakan adanya kelangkaan barang baik dengan cara menimbun stock atau mengenakan entry barriers. Kemudian menjual dengan harga tinggi dibandingkan harga sebelum munculnya kelangkaan. Selain itu, mengambil keuntungan yang lebih tinggi dibandingkan keuntungan sebelum komponen 1 dan 2 dilakukan.

\section{Kebijakan Pemerintah Pemerintah dalam Mengatasi ihtikar}

Apabila telah terjadi penimbunan barang, maka pemerintah berhak memaksa para pedagang untuk menjual barang tersebut dengan harga standar yang berlaku dipasar. Bahkan, menurut para ulama, barang yang ditimbun oleh para pedagang dijual dengan harga modalnya dan pedagang tersebut tidak dibenarkan mengambil keuntungan sebagai hukuman terhadap mereka. Sekiranya para pedagang itu enggan menjual barangnya dengan harga pasar, maka pihak penegak hukum (hakim) dapat menyita barang itu dan kemudian membagikannya kepada masyarakat yang memerlukannya. Pihak pemerintah seharusnya setiap 
saat memantau dan mengantisipasi, agar tidak terjadi ihtikar dalam setiap komoditas, manfaat dan jasa yang dapat diperlukan masyarakat.

Harga standar yang tidak memberatkan masyarakat dan merugikan pedagang harus dipadukan, dan tidak sampai menguntungkan sepihak, masyarakat atau pedagang. Menurut Fathi a-Duraini (1997), bahwa pemerintah tidak dibenarkan mengeksport bahan kebutuhan warganya sampai tidak ada lagi yang dikonsumsikan oleh masyarakat, sehingga membawa kemudharatan. Pengeksporan barang-barang yang diperlukan masyarakat pada dasarnya sama dengan ihtikar dari segi akibat yang dirasakan oleh masyarakat. Lebih para lagi, apabila barang-barang itu diselundupkan ke luar negeri (tidak legal) seperti minyak tanah (BBM), padahal masyarakat betul-betul sangat memerlukannya. Fathi ad-Duraini menyatakan, bahwa ada kaidah fiqih yang berkaitan dengan fungsi penguasa, yaitu: "Tindakan penguasa harus senantiasa mengacu kepada kemaslahatan orang banyak."

\section{METODE}

Penelitian ini dilaksanakan pada daerah-daerah yang menjadi tujuan PT. Petrokimia Gresik pada alokasi pupuk bersubsidi, daerah khusus adalah Jawa Timur. Adapun data yang digunakan dalam penyusunan hasil penelitian ini adalah berupa data primer dan data sekunder. Data primer, adalah data yang diperoleh langsung dari PT. Petrokimia Gresik melalui wawancara dengan pimpinan perusahaan, maupun manajer pemasaran, meliputi informasi distribusi pupuk bersubsidi. Data sekunder, adalah data yang dipublikasikan bukan data yang diproteksi. Meliputi ongkos transportasi, jumlah pengiriman dan daerah pengiriman, dan lain sebagainya.

Sedangkan analisis data untuk menjawab tujuan adalah sebagai berikut: (a) Metode Pojok Barat Laut (North West Corner Methode) Distribusi Pupuk Bersubsidi, (b) Cara Modi (Modified Distribution Methode) Distribusi Pupuk Bersubsidi, (c) Sedangkan untuk menjawab tujuan kedua digunakan pendekatan ekonomi Islam yang berlandaskan Al-Qur;an dan Al-Hadist.

\section{HASIL DAN PEMBAHASAN}


Tabel 1.

Rekapitulasi Kebutuhan Pupuk Subsidi ZA di masing-masing Kabupaten

\begin{tabular}{|c|c|c|c|}
\hline No & $\begin{array}{c}\text { Dari Gresik ke ..(luas } \\
\text { lahan...Ha) }\end{array}$ & $\begin{array}{l}\text { Kebutuhan } \\
\text { Pupuk } \\
\text { ZA (ton) (a) }\end{array}$ & $\begin{array}{l}\text { Biaya Pengangkutan } \\
\text { (ribu Rp.) (b) }\end{array}$ \\
\hline 1 & $\begin{array}{l}\text { Pacitan (luas lahan } \\
16.020 \mathrm{Ha} \text { ) }\end{array}$ & 108.936 & 6.209 .352 \\
\hline 2 & Ponorogo (1.923 Ha) & $13.076,4$ & $745.354,8$ \\
\hline 3 & Trenggalek (4.391 Ha) & $29.858,8$ & $1.701 .951,6$ \\
\hline 4 & Tulungagun(3.152Ha) & $21.433,6$ & 1221715,2 \\
\hline 5 & Blitar (3.219 Ha) & $21.889,2$ & $1.247 .684,4$ \\
\hline 6 & Kediri (336 Ha) & $2.284,8$ & $130.233,6$ \\
\hline 7 & Malang (7.219 Ha) & $49.089,2$ & $2.798 .084,4$ \\
\hline 8 & Lumajang (5.212 Ha) & $35.441,6$ & $2.020 .171,2$ \\
\hline 9 & Jember (1.600 Ha) & 10.880 & 620.160 \\
\hline 10 & Banyuwangi $(1.722 \mathrm{Ha})$ & $11.709,6$ & $667.447,2$ \\
\hline 11 & Bondowoso $(3.047 \mathrm{Ha})$ & $20.719,6$ & $1.181 .017,2$ \\
\hline 12 & Situbondo (496 Ha) & $3.372,8$ & $192.249,6$ \\
\hline 13 & Probolinggo $(5.254 \mathrm{Ha})$ & 5.254 & $2.036 .450,4$ \\
\hline 14 & Pasuruan $(4.020 \mathrm{Ha})$ & 27.336 & 1.558 .152 \\
\hline 15 & Mojokerto $(719 \mathrm{Ha})$ & $4.889,2$ & $278.684,4$ \\
\hline 16 & Jombang (442 Ha) & $3.005,6$ & $171.319,2$ \\
\hline 17 & Nganjuk (4.182 Ha) & 28.437 & $1.620 .943,2$ \\
\hline 18 & Madiun $(4.945 \mathrm{Ha})$ & 33.626 & 1.916 .682 \\
\hline 19 & Magetan $(129 \mathrm{Ha})$ & 877,2 & $50.000,4$ \\
\hline 20 & Ngawi (845 Ha) & 5.746 & 327.522 \\
\hline 21 & Bojonegoro $(8.846 \mathrm{Ha})$ & $60.152,8$ & $3.428 .709,8$ \\
\hline 22 & Tuban (1.275 Ha) & 8.670 & 494.190 \\
\hline 23 & Lamongan (5.932 Ha) & $40.337,6$ & $2.299 .243,2$ \\
\hline
\end{tabular}




\begin{tabular}{|l|l|c|c|}
\hline 24 & Gresik (332 Ha) & 2.257 & $128.683,2$ \\
\hline 25 & Bangkalan (4.310 Ha) & 29.308 & 1.670 .556 \\
\hline 26 & Sampang (10.205 Ha) & 69.394 & 3.955 .458 \\
\hline 27 & Pamaekasan (12.120Ha) & 82.416 & 4.697 .712 \\
\hline 28 & Sumenep (5.002 Ha) & $34.013,6$ & $1.938 .775,2$ \\
\hline
\end{tabular}

Keterangan:

(a) Luas lahan untuk padi pada kabupaten dikalikan kebutuhan ZA per hektar per ton sebanyak 6,8 ton.

(b) Hasil perkalian pada point (a) dikalikan biaya Rp.57.000/ton

Tabel 2. Hasil Analisis Initial Solution by Northwest Corner Method

\begin{tabular}{|l|l|l|l|l|l|}
\hline & \multicolumn{1}{|c|}{ Pacitan } & Ponorogo & Trenggalek & Tulungagung & \multicolumn{1}{|c|}{ Blitar } \\
\hline Lini I & 31046760.0 & 3726774.0 & 8509758.0 & 2025207.0 & 0.0 \\
\hline Lini Iia & 0.0 & 0.0 & 0.0 & 4083369.0 & 6238422.0 \\
\hline Lini Iib & 0.0 & 0.0 & 0.0 & 0.0 & 0.0 \\
\hline Lini III & 0.0 & 0.0 & 0.0 & 0.0 & 0.0 \\
\hline Lini IV & 0.0 & 0.0 & 0.0 & 0.0 & 0.0 \\
\hline
\end{tabular}

Distribusi dari lini I (S1) optimalnya hanya pada kabupaten Blitar, pada lini IIa (S2) adalah kabupaten Pacitan, Ponorogo dan Trenggalek. Sedangkan kabupaten Tulungagung kebutuhan pupuk ZA sebanyak 1.221.715,2 ton dan menjadikan kondisi optimal, maka kekurangannya sebanyak 2.381.417,4 ton dan kabupaten Blitar kebutuhan pupuknya sebanyak 1.247.684,4 ton, maka kekurangannya sebanyak $61.136 .535,6$ ton.

Tabel 3. Hasil Analisis Initial Solution by Northwest Corner Method

\begin{tabular}{|l|l|l|l|l|l|}
\hline & \multicolumn{1}{|c|}{ Kediri } & \multicolumn{1}{|c|}{ Malang } & \multicolumn{1}{|c|}{ Lumajang } & \multicolumn{1}{|c|}{ Jember } & Banyuwangi \\
\hline Lini I & 0.0 & 0.0 & 0.0 & 0.0 & 0.0 \\
\hline Lini Iia & 651168.0 & 13990422.0 & 10100856.0 & 3100800.0 & 3337236.0 \\
\hline Lini Iib & 0.0 & 0.0 & 0.0 & 0.0 & 0.0 \\
\hline Lini III & 0.0 & 0.0 & 0.0 & 0.0 & 0.0 \\
\hline Lini IV & 0.0 & 0.0 & 0.0 & 0.0 & 0.0 \\
\hline
\end{tabular}

Distribusi dari lini I (S1), lini IIb, III dan IV telah menunjukkan optimal. Sedangkan pada lini IIa (S2) adalah kabupaten Kediri, Malang, Lumajang, Jember, Banyuwangi. Dari 5 kabupaten tersebut kebutuhan pupuk bersubsi ZA 
berturut-turut sebanyak $2.284,8$ ton, $49.089,2$ ton, $35.441,6$ ton, 10.880 ton dan 11.709,6 ton dan untuk menjadikan kondisi optimal, maka kabuapaten Kediri, Malang, Lumajang, Jember dan Banyuwangi kekuranng berturut turut sebanyak $648.883,2$ ton, $13.941 .332,8$ ton, , 10.065.44,4 ton, 3.089.920 ton dan 3325526,4 ton.

Tabel 4. Hasil Analisis Initial Solution by Northwest Corner Method

\begin{tabular}{|l|l|l|l|l|l|}
\hline & Bondowoso & Situbondo & Probolinggo & Pasuruan & Mojokerto \\
\hline Lini I & 0.0 & 0.0 & 0.0 & 0.0 & 0.0 \\
\hline Lini Iia & 3806226.0 & 0.0 & 0.0 & 0.0 & 0.0 \\
\hline Lini Iib & 2098860.0 & 961248.0 & 10182252.0 & 7790760.0 & 1393422.0 \\
\hline Lini III & 0.0 & 0.0 & 0.0 & 0.0 & 0.0 \\
\hline Lini IV & 0.0 & 0.0 & 0.0 & 0.0 & 0.0 \\
\hline
\end{tabular}

Tabel 5. Hasil Analisis Initial Solution by Northwest Corner Method

\begin{tabular}{|l|l|l|l|l|l|}
\hline & Jombang & \multicolumn{1}{|c|}{ Nganjuk } & \multicolumn{1}{|c|}{ Madiun } & Magetan & \multicolumn{1}{c|}{ Ngawi } \\
\hline Lini I & 0.0 & 0.0 & 0.0 & 0.0 & 0.0 \\
\hline Lini Iia & 0.0 & 0.0 & 0.0 & 0.0 & 0.0 \\
\hline Lini Iib & 856596.0 & 8104716.0 & 9583410.0 & 250002.0 & 1637610.0 \\
\hline Lini III & 0.0 & 0.0 & 0.0 & 0.0 & 0.0 \\
\hline Lini IV & 0.0 & 0.0 & 0.0 & 0.0 & 0.0 \\
\hline
\end{tabular}

Tabel 6. Hasil Analisis Initial Solution by Northwest Corner Method

\begin{tabular}{|l|l|l|l|l|l|}
\hline & Bojonegoro & \multicolumn{1}{|c|}{ Tuban } & \multicolumn{1}{|c|}{ Lamongan } & \multicolumn{1}{c|}{ Gresik } & \multicolumn{1}{c|}{ Bangkalan } \\
\hline Lini I & 0.0 & 0.0 & 0.0 & 0.0 & 0.0 \\
\hline Lini Iia & 0.0 & 0.0 & 0.0 & 0.0 & 0.0 \\
\hline Lini Iib & 2449623.0 & 0.0 & 0.0 & 0.0 & 0.0 \\
\hline Lini III & 14693926.0 & 2470950.0 & 11496216.0 & 643416.0 & 8352780.0 \\
\hline Lini IV & 0.0 & 0.0 & 0.0 & 0.0 & 0.0 \\
\hline
\end{tabular}

Tabel 7. Hasil Analisis Initial Solution by Northwest Corner Method

\begin{tabular}{|l|l|l|l|l|c|}
\hline & Sampang & Pamekasan & Sumenep & Demand & Supply \\
\hline Lini I & 0.0 & 0.0 & 0.0 & 0.0 & 45308499.0 \\
\hline Lini Iia & 0.0 & 0.0 & 0.0 & 0.0 & 45308499.0 \\
\hline Lini Iib & 0.0 & 0.0 & 0.0 & 0.0 & 45308499.0 \\
\hline Lini III & 7651211.0 & 0.0 & 0.0 & 0.0 & 45308499.0 \\
\hline Lini IV & 11126079.0 & 23488560.0 & 9693876.0 & 999984.0 & 45308499.0 \\
\hline
\end{tabular}

Tabel 8. Hasil Analisis Initial Solution by Modi

\begin{tabular}{|l|l|l|l|l|c|}
\hline & Pacitan & Ponorogo & Trenggalek & Tulungagung & Blitar-D5 \\
\hline
\end{tabular}




\begin{tabular}{|l|l|l|l|l|l|}
\hline Lini I & 0.0 & 3726774.0 & 8509758.0 & 4124067.0 & 0.0 \\
\hline Lini Iia & 0.0 & 0.0 & 0.0 & 1984509.0 & 6238422.0 \\
\hline Lini Iib & 0.0 & 0.0 & 0.0 & 0.0 & 0.0 \\
\hline Lini III & 31046760.0 & 0.0 & 0.0 & 0.0 & 0.0 \\
\hline Lini IV & 0.0 & 0.0 & 0.0 & 0.0 & 0.0 \\
\hline
\end{tabular}

Tabel 9. Hasil Analisis Initial Solution by Modi

\begin{tabular}{|l|l|l|l|l|l|}
\hline & \multicolumn{1}{|c|}{ Kediri-D6 } & \multicolumn{1}{|c|}{ Malang } & \multicolumn{1}{c|}{ Lumajang } & \multicolumn{1}{c|}{ Jember } & \multicolumn{1}{c|}{ Banyuwangi } \\
\hline Lini I & 0.0 & 0.0 & 0.0 & 0.0 & 0.0 \\
\hline Lini Iia & 651168.0 & 13990422.0 & 10100856.0 & 3100800.0 & 3337236.0 \\
\hline Lini Iib & 0.0 & 0.0 & 0.0 & 0.0 & 0.0 \\
\hline Lini III & 0.0 & 0.0 & 0.0 & 0.0 & 0.0 \\
\hline Lini IV & 0.0 & 0.0 & 0.0 & 0.0 & 0.0 \\
\hline
\end{tabular}

Tabel 10 . Hasil Analisis Initial Solution by Modi

\begin{tabular}{|l|l|l|l|l|l|}
\hline & $\begin{array}{l}\text { Bondowoso }- \\
\text { D11 }\end{array}$ & Situbondo & Probolinggo & Pasuruan & Mojokerto \\
\hline Lini I & 0.0 & 961248.0 & 10182252.0 & 1451566.0 & 0.0 \\
\hline Lini Iia & 5905086.0 & 0.0 & 0.0 & 0.0 & 0.0 \\
\hline Lini Iib & 0.0 & 0.0 & 0.0 & 6339194.0 & 1393422.0 \\
\hline Lini III & 0.0 & 0.0 & 0.0 & 0.0 & 0.0 \\
\hline Lini IV & 0.0 & 0.0 & 0.0 & 0.0 & 0.0 \\
\hline
\end{tabular}

Tabel 11 . Hasil Analisis Initial Solution by Modi

\begin{tabular}{|l|l|l|l|l|l|}
\hline & $\begin{array}{l}\text { Jombang- } \\
\text { D16 }\end{array}$ & Nganjuk & Madiun & Magetan & Ngawi \\
\hline Lini I & 0.0 & 0.0 & 0.0 & 0.0 & 0.0 \\
\hline Lini Iia & 0.0 & 0.0 & 0.0 & 0.0 & 0.0 \\
\hline Lini Iib & 856596.0 & 8104716.0 & 9583410.0 & 250002.0 & 1637610.0 \\
\hline Lini III & 0.0 & 0.0 & 0.0 & 0.0 & 0.0 \\
\hline Lini IV & 0.0 & 0.0 & 0.0 & 0.0 & 0.0 \\
\hline
\end{tabular}

Tabel 12 . Hasil Analisis Initial Solution by Modi

\begin{tabular}{|l|l|l|l|l|l|}
\hline & $\begin{array}{l}\text { Bojonegoro- } \\
\text { D21 }\end{array}$ & Tuban & Lamongan & Gresik & Bangkalan \\
\hline Lini I & 0.0 & 2470950.0 & 11496216.0 & 643416.0 & 1742252.0 \\
\hline Lini Iia & 0.0 & 0.0 & 0.0 & 0.0 & 0.0 \\
\hline Lini Iib & 17143549.0 & 0.0 & 0.0 & 0.0 & 0.0 \\
\hline Lini III & 0.0 & 0.0 & 0.0 & 0.0 & 6610528.0 \\
\hline Lini IV & 0.0 & 0.0 & 0.0 & 0.0 & 0.0 \\
\hline
\end{tabular}

Tabel 13 . Hasil Analisis Initial Solution by Modi 


\begin{tabular}{|l|l|l|l|l|c|}
\hline & Sampang & Pamekasan & Sumenep & Demand & Supply \\
\hline Lini I & 0.0 & 0.0 & 0.0 & 0.0 & 45308499.0 \\
\hline Lini Iia & 0.0 & 0.0 & 0.0 & 0.0 & 45308499.0 \\
\hline Lini Iib & 0.0 & 0.0 & 0.0 & 0.0 & 45308499.0 \\
\hline Lini III & 7651211.0 & 0.0 & 0.0 & 0.0 & 45308499.0 \\
\hline Lini IV & 11126079.0 & 23488560.0 & 9693876.0 & 999984.0 & 45308499.0 \\
\hline
\end{tabular}

Initial solution: 665578033590000.0 (Multiple Optimum Solution)

\section{Minimisasi Praktek Penimbunan (Ihtikar) dalam Islam}

Sebagaimana disebutkan sebelumnya bahwa ihtikar (penimbunan) merupakan upaya untuk merusak mekanisme pasar yang sehat untuk mendapatkan keuntungan secara tidak fair dan hal tersebut termasuk perbuatan yang diharamkan oleh syara', karena membawa mudharat yang besar terhadap masyarakat dan negara, baik dari aspek distribusi barang sehingga terjadi kelangkaan barang maupun mekanisme harga yang dhalim karena hanya ditentukan secara sepihak, yaitu dari aspek suplay saja. Hal demikian juga bertentangan dengan prinsip transaksi dalam Islam yang selalu menekankan prinsip "taradlin" (suka sama suka) sebagaimana yang ditegaskan dalam al-Quran Surat al-Nisa' ayat 29.

Apabila penimbunan suatu barang telah terjadi di pasar, maka pemerintah berhak memaksa pedagang untuk menjualnya dengan harga normal pada saat itu. Bahkan menurut ulama fikih, para pedagang menjual barang tersebut dengan harga modal sebagai hukumannya, karena mereka tidak berhak mengambil untung. Di samping bertindak tegas, pemerintah sejak semula seharusnya dapat mengantisipasi agar tidak terjadi ihtikar dalam setiap komoditi, manfaat atau jasa yang sangat dibutuhkan masyarakat (al-Nawawi, 1978). Oleh karena itu, sejak dahulu dalam sejarah Islam sudah ada sebuah lembaga yang menjaga, mengontrol dan mengawasi mekanisme pasar untuk mencegah terjadinya apa yang disebut dengan istilah distorsi pasar, lembaga tersebut dikenal dengan lembaga Hisbah (lembaga pengawas pasar). Selain mengawasi dan mengontrol pasar, lembaga tersebut juga bisa membuat kebijakan, atau semacam regulasi yang mengatur bagaimana mekanisme pasar bisa berjalan dengan fair, khususnya dalam masalah transaksi dan distribusi barang, bahkan dapat memberikan sanksi bagi para pelaku pasar yang melanggar regulasi dan dianggap "nakal”. 
Fungsi lembaga hisbah untuk mencegah terjadinya distorsi pasar, salah satunya pernah dilakukan oleh Khalifah Umar bin Khattab yang pernah menertibkan beberapa fenomena yang menyimpang pada masa itu, yaitu fenomena berbuat curang dalam timbangan atau mengurangi timbangan (mark up) dalam praktek jual beli.

Berdasarkan pendapat tersebut, walaupun pada prinsipnya pemerintah atau penguasa tidak diperbolehkan melakukan intervensi harga, namun hal itu bisa dibenarkan dalam kondisi tertentu, misalnya pada saat terjadi distorsi pasar ketika mekanisma pasar tidak berjalan secara normal. Beliau membolehkan intervensi harga jika terjadi kedhaliman (eksploitasi) yang disebut dengan distorsi pasar, yaitu ketika mekanisme supply dan demand tidak berjalan secara normal. Sehingga dari sini diketahui mengapa monopoli partikelir (bisnis) dilarang, hal itu karena fungsi suply barang tidak berjalan normal dengan dikuasai oleh satu orang. Monopoli partikelir juga dilarang karena mematikan persaingan ekonomi, sehingga cenderung menghambat kreativitas dan kemajuan ekonomi. Di samping itu, monopoli partikelir juga menjadikan harta akan berputar di kalangan kelompok tertentu saja.

Distorsi pasar bisa saja terjadi akibat ulah sebagian pelaku pasar untuk mengendalikan mekanisme suplay and demand sehingga tidak berjalan secara alami. Hal ini dilakukan untuk mendapatkan keuntungan melalui cara yang tidak sehat, baik melalui cara penimbunan, spekulasi, pemusnahan, maupun talaqqi rukban. Dalam kondisi ini pemerintah berkewajiban untuk menjaga stabilitas harga sesuai dengan hukum pasar yang sehat, sehingga intervensi harga pun sebenarnya diperbolehkan untuk mencegah adanya distorsi pasar tersebut. Misalnya, ketika ada pengumuman bahwa harga pupuk akan naik, masyarakat terutama para penjual pupuk eceran ramai-ramai antri menyerbu distributor induk untuk ditimbun dengan harapan mendapatkan keuntungan di atas harga wajar. Akibatnya pupuk menjadi langka, dan benar juga ketika stok pupuk habis, mereka menjual pupuk tersebut dengan harga yang tinggi. Kelangkaan sekaligus kenaikan harga tidak wajar terhadap pupuk yang diakibatkan adanya penimbunan niscaya tidak akan terjadi, apabila pemerintah menetapkan harga eceran sama dengan harga distributor induk, sekaligus memberi sangsi bagi setiap yang melanggar 
ketentuan harga tersebut. Dengan adanya intervensi pemerintah tersebut, diharapkan tidak terjadi penimbunan atau kenaikan harga yang tidak wajar, karena penjual (distributor) akan berpikir untuk apa ramai-ramai antri untuk menimbun kalau harganya ditetapkan sama.

Penepatan harga boleh juga dilakukan dalam kerangka kebijakan yang berkaitan dengan kesejahteraan masyarakat banyak, misalnya, penetapan harga pupuk yang disubsidi. Biasanya pemerintah melakukan monopoli di dalamnya, sehingga monopoli pun sebenarnya tidak dilarang sepanjang tidak untuk dinikmati oleh sekelompok orang saja (bisnis/partikelir). Hal ini sama halnya dengan intervensi harga untuk melindungi dan mengindari terjadinya eksploitasi terhadap kelompok tertentu (biasanya kelompok lemah). Misalnya dengan menetapkan UMR, harga dasar gabah/beras dll. Kenyataan diperbolehkannya melakukan intervensi harga tersebut tentu didasarkan pada situasi dan kondisi khusus yang berbeda dengan kondisi pada umumnya. Kesimpulan ini bisa dipahami dari konteks hadis di atas yang mengancam orang yang melakukan intervensi harga yang memberatkan atau merugikan masyarakat banyak.

Sehingga mafhum mukhalafah (logika hukum terbalik)-nya, setiap intervensi harga yang dilakukan untuk menghindarkan eksploitasi, distorsi pasar, atau justru untuk kesejahteraan masyarakat banyak niscaya tidak dilarang dalam konteks hadis tersebut. Inilah yang membedakan dengan ekonomi kapitalis, yang memberikan kebebasan mutlak kepada pasar untuk menentukan harga terlepas apakah hal tersebut berdampak kepada kemaslahatan masyarakat banyak atau tidak. Adam Smith (1737-1790 M) memperkenalkan apa yang kini dikenal dengan sistem ekonomi liberal kapitalis, yang digagas oleh Smith untuk menentang sistem ekonomi merkantilisme, yang sangat menekankan campur tangan pemerintah dalam memajukan perekonomian. Smith mengajukan teorinya tentang peran negara yang sangat terbatas hanya pada pemeliharaan ketertiban, perlindungan hukum dan perlindungan keamanan. Ia menghendaki sebuah pasar bebas yang bergerak secara alami yang ditentukan oleh apa yang dia sebut sebagai the invisible hand (tangan ajaib). Selanjutnya Smith dikenal sebagai bapak paham laissez-faire (Munir, 2007). 
Smith juga memahami keadilan sebagai kebebasan individu untuk menjalankan dan memaksimalkan potensi dirinya sesuai dengan kehendaknya, selagi tidak merugikan orang lain. Ia menganggap bahwa prinsip utama keadilan adalah no harm atau prinsip tidak melukai dan merugikan orang lain (Munir, 2007). Ia memahami kebebasan manusia dalam pengertian negatif dan positif. Kebebasan negatif adalah tidak adanya campur tangan atau hambatan dari luar, khususnya dalam bentuk campur tangan pemerintah. Sedang kebebasan positif adalah individu harus dibiarkan untuk melakukan apa saja yang mereka kehendaki sesuai dengan apa yang mereka anggap baik. Ia menolak campur tangan dan kontrol pemerintah atas kegiatan ekonomi setiap orang secara apriori karena merugikan.

Kalau pada dasarnya intervensi harga dilarang dalam Islam, maka intervensi pasar diperbolehkan untuk menjaga stabilitas harga. Hal tersebut sebagaimana yang diakukan oleh Khalifah Umar bin Khattab ketika terjadi kenaikan harga barang-barang di Madinah yang memberatkan kaum muslimin yang diakibatkan faktor yang genuine. Untuk mengatasi hal tersebut, Khalifah Umar bin Khattab melakukan intervensi pasar dengan mengimpor sejumlah besar barang dari Mesir ke Madinah. Jadi intervensi langsung dilakukan melalui penyediaan jumlah barang yang ditawarkan. Namun demikian, rendahnya daya beli kaum muslimin saat itu memaksa Umar mengeluarkan sejenis kupon yang dibagikan kepada mereka yang berhak (Karim 2002).

\section{KESIMPULAN DAN SARAN}

\section{Kesimpulan}

Optimalisasi dapat dicapai apabila dalam melaksanakan perencanaan untuk mengajukan droping pupuk secara tepat dan jelas. Kesalahan dalam perencanaan terutama mengajukan usulan droping pupuk menjadikan sering terjadinya kekurangan pupuk pada setiap Kabupaten yang bersangkutan. Jika ini terjadi, maka perlu dilakukan realokasi distribusi baik kekurangan dan kelebihan. Adanya realokasi inilah adalah kemungkinan (propabilty) terjadi praktek monopoli/ikhtikar.

Islam sangat konsen terhadap masalah ketersediaan barang dan distribusinya di kalangan masyarakat, sehingga banyak nash-nash agama (baik dari al-Quran maupun sunnah) yang mengecam dan melarang secara tegas terhadap segala bentuk ihtikar (penimbunan), dan segala bentuk praktek yang mengarah kepada ihtikar, seperti 
monopoli dan persaingan tidak sehat dalam mekanisme pasar. Bahkan, apabila telah terjadi penimbunan barang, maka pemerintah berhak memaksa para pedagang untuk menjual barang tersebut dengan harga standar yang berlaku di pasar. Bahkan, menurut para ulama, barang yang ditimbun oleh para pedagang dijual dengan harga modalnya dan pedagang tersebut tidak dibenarkan mengambil keuntungan sebagai hukuman terhadap mereka. Sekiranya para pedagang itu enggan menjual barangnya dengan harga pasar, maka pihak penegak hukum (hakim) dapat menyita barang itu dan kemudian membagikannya kepada masyarakat yang memerlukannya.

\section{Saran:}

Pada pihak wanga terlibat langsung dalam penyusunan usulan droping pupuk, dari tingkat desa, kecamatan dan kabupaten hendaknya mengalisis betul kebutuhan pupuk oleh petani produsen. hal ini dapat dilakukan dengan bersinergi antara aparat desa bagian ekonomi, penyuluh pertanian dan kelompok tani sehingga kekurangan dan kelebihan pupuk pada daerah tersebut dapat diminimisasi.

Pihak pemerintah seharusnya setiap saat memantau sekaligus mengantisipasi, agar tidak terjadi ihtikar (penimpunan) maupun praktek-praktek yang mengarah kepada penimbunan, seperti monopoli dalam distribusi pupuk bersubsidi, sehingga perlu dibentuk sebuah satuan tugas/unit yang secara khusus mengawasi dan melakukan kontrol terhadap distribusi pupuk bersubsidi, karena faktanya minimnya pengawasan telah banyak merugikan negara (karena beban subsidi pupuk telah menguras dana trilyunan rupiah dari APBN) maupun rakyat kecil yang sangat membutuhkan insentif pemerintah untuk mendapatkan pupuk yang murah, namun seringkali mereka tetap saja mengalami kelangkaan pupuk (sehingga mereka juga harus membeli harga yang lebih mahal dari harga subsidi), karena ulah dan permainan beberapa oknum khususnya para distributor.

\section{DAFTAR PUSTAKA}

Al-Baghawi, 1976. Syarh al-Sunnah. Maktabah Musthafa al-babi al-Halabi, Kairo Al-Nawawi, Muhyiddin bin Syaraf. 1980. Syarh Shahih Muslim. Maktabah Musthafa al-Babi al-Halabi, Kairo

Al-Nawawi, Muhyidin bin Syarof. 1978. Al-Majmu' Syarh al-Muhadzab. Dar alNahdlah al-Mishriyyah, Kairo. 
Al-Quran al-Karim (Program Holy Quran dan Program Al-Qur an Indeks)

Karim, Adiwarman. 2002. Ekonomi Mikro Islami. Penerbit IIIT Indonesia, Jakarta

Munir, Misbahul. 2007. Ajaran-Ajaran Ekonomi Rasulullah. Penerbit UIN Malang Press, Malang.

Nur Diana, Ilfi. Hadits-Hadits Ekonomi. Penerbit UIN Malang Press, Malang

Siagian, P(1987). Penelitian Operasional. Jakarta: UI-PRESS.

Program Mausu'ah al-Hadits al-Syarif fi al-Kutub al-Sittah

http://www.petrokimia-gresik.com/ 